\title{
RELACIONES DE LA IGLESIA Y EL ESTADO EN LA NUEVA CONSTITUCION DEL PERU
}

Francisco Interdonato S.J.

\section{INTRODUCCION}

La articulación de las relaciones entre el Estado y la Iglesia, o el de la libertad religiosa en la esfera de la política, tiene una historia larga, oscilante, aún por parte de la Iglesia. Esto último no debe extrañar porque no se trata de cuestiones de pura revelación sobrenatural, infalible, sino del llamado "objeto secundario" del Magisterio, esto es, de verdades conexas con la Revelación en las que una premisa es tomada de ella, pero la otra pertenece a una disciplina natural y humana, esencialmente mudable, cual es una teoría socio-política, la configuración de la sociedad en una determinada época, etc. Estas no privan de su verdad a la Iglesia, pero sí la condicionan, oponen resistencia a su despliegue.

Por tanto no hay motivo para suponer que la configuración actual promovida por el Vaticano II sea un golpe más de timón que vira de la derecha a la izquierda, o al revés. Por primera vez el rumbo lo ha fijado un Concilio Ecuménico y, por parte de la iglesia, permanecerá. Se espera que también por parte de los Estados. ¿Cuál ha sido? Trataremos de explicarlo breve y claramente en estos cuatro puntos: 10 . la Doctrina del Vaticano II, acerca de las relaciones de la Iglesia y el Estado hoy; 20. ¿A qué debe renunciar, consecuentemente, la Iglesia? ; 3o. ¿A qué debe renunciar (o qué debe cumplir) el Estado? ; 40. ¿Cómo realizaron en el Perú la iglesia y el Estado esas renuncias $o$, más en concreto, cómo se reflejan en las normas fundamentales de la nueva Constitución?

\section{DOCTRINA DEL VATICANO II}

La importancia y la cuidadosa elaboración de esta doctrina se descubre en la historia interna del Concilio. Comenzó por abordar el tema en la Constitución Dogmática sobre la iglesia ("Lumen Gentium") en cuyo esquema primitivo figuraba un párrafo titulado "Relaciones de la Iglesia y el Estado". Los Padres vieron que con lo que se podía establecer en tal contexto -recogido en el No. 36 de dicha Constitución - no podía quedar agotado. Se retomó el asunto en la Constitución Pastoral sobre la Iglesia ("Gaudium et Spes") con más amplitud (nn. 36 y 76), pero para constatar más claramente la misma insuficiencia. Finalmente decidieron tratarlo íntegramente y decirlo a todos los vientos en un peculiar documento que figura como la primera de las "Declaraciones": La "Dignitatis Humanae" ("De la dignidad de la persona humana").

En lugar de "relaciones entre la Iglesia y el Estado", se la tituló "Declaración sobre la libertad religiosa", por expresar mejor su enraizamiento en la dignidad humana y también porque el Concilio - que manda conceder en los países de mayoría católica la plena libertad religiosa a todos-, pretendió 
reinvindicarla de parte de aquella casi mitad del mundo que desconoce y combate la libertad religiosa simplemente dicha (no sólo de los católicos o de los cristianos, sino también de los judios o de los musulmanes)(1).

La doctrina del Vaticano II en los Documentos mencionados es:

a) "Lumen Gentium": Cap. IV, No. 36; 10.).- Establece la exigencia de la libertad religiosa y, por consiguiente, la separación de la Iglesia y el Estado; 2o) Sin embargo, esa separación no puede ser absoluta, completa; primero porque el mismo ciudadano lo es tanto del Estado como de la Iglesia, y segundo porque el propio Estado, en cuanto realidad humana creada, está ordenado a Dios y debe integrarse en el orden establecido por Dios;

B) "Gaudium et Spes": Recoge el fondo de lo dicho en la L.G. con otros términos: 10) Consagra la autonomía del Estado (de las “realidades terrenas"); 2o) Rechaza explícitamente que dicha autonomía se pueda entender como independencia de Dios (No. 36); y, 3o) Añade una razón pastoral: ambos (Estado e Iglesia) están al servicio del hombre;

C) “Declaración sobre la libertad religiosa" ("D.H.”): El No. 2 propone las tres proposiciones fundamentales: 1a.: La persona humana tiene derecho a la libertad religiosa; 2a.: Esa libertad religiosa consiste en estar inmune de coacción; 3a.: Ese derecho está fundado en la dignidad de la persona humana. Hagamos una breve explicación de los tres.

La 1a. y 2a. son directamente interdependientes, ya que la libertad religiosa consiste en estar inmune de coacción. Nótese que trata de la libertad del acto interior de fe que procede inmediatamente de la voluntad, $y$ que por tanto no puede ser coaccionado ni aun por el mismo Dios. La coacción en este caso equivaldría a una violación interna de la naturaleza misma del ser libre, esto es, a la supresión de la esencia del hombre. En otras palabras, Dios no pudo querer libre al hombre y a la vez suprimir dicha libertad.

El Concilio, pues, habla obviamente, de la libertad llamada de Espontaneidad y de Ejecución. Contra éstas cabe la coacción exterior ejercida por un elemento extrínseco, en este caso por la autoridad. En este último sentido la libertad religiosa consiste: Negativamente en a) no querer obligar (por parte de la autoridad) a nadie a ir contra su propia conciencia; y b) no ser impedido (el individuo) - con ninguna clase de presión- de actuar conforme a su propia conciencia. Positivamente consiste en disponer de los medios previos para poder decidir libremente sobre su opción religiosa.

(1) Es cierto que la casi totalidad de las Constituciones de los paises socialistas (excepto Albania y no sabemos si algún otro) reconoce no la libertad religiosa sino la libertad de cultos. Aun allí donde eso se cumple adecuadamente - por ejemplo, en Poloniala diferencia entre ambas libertades es absolutamente substancial Aquí, por no ser ese nuestro tema, nos abstenemos de explicarlo. 
3a. proposición: este derecho está fundado en la dignidad de la persona porque ésta, sin libertad religiosa, es privada de su prerrogativa más esencial: poder disponer de sí mismo como totalidad frente al mundo, a los otros y a Dios.

\section{II. ¿A QUE PRIVILEGIOS IOTORGADOS POR LA CONSTITUCION DE 33) DEBIA RENUNCIAR Y RENUNCIO LA IGLESIA?}

La libertad religiosa - como toda libertad- si no se convierte en ley podrá quedar perfectamente jaqueada, supuesto que siempre habrá mayorias y minorías, fuertes y débiles. Por otra parte la autoconciencia del hombre actual se crispa más que nunca contra los privilegios, con mayor intensidad experimenta que la dicha tiene aún sabor de libertad.

El Concilio, consciente de ello, tomó la iniciativa en quitar todo obstáculo a la libertad religiosa proclamada para todas las confesiones, es decir, para todas las religiones, y dando ejemplo a los Estados y a las otras religiones, comenzó por renunciar a los privilegios de que la Iglesia Católica pudiera gozar en los países de mayoria católica: "La Iglesia - dice- no pone su esperanza en privilegios dados por el poder civil; más aún, renunciará al ejercicio de ciertos derechos legítimamente adquiridos tan pronto como conste que su uso puede empañar la pureza de su testimonio o las nuevas condiciones de vida exijan otra disposición"“"G.S. No. 76).

De conformidad con este principio la Iglesia peruana propuso a la Asamblea Constituyente eliminar de la nueva Constitución el privilegio, moderado pero todavía excluyente, que le otorgaba el Art. 2320. de la Constitución de 1933 que rezaba asi: "Respetando los sentimientos de la mayoría nacional, el Estado protege la Religión Católica, Apostólica y Romana. Las demás religiones, gozan de libertad para el ejercicio de sus respectivos cultos".

Teológica y jurídicamente no se puede hablar de verdadera libertad religiosa si el Estado protege a una religión en particular. Pero -obsérvese cuidadosamente- porque fue una confusión en que muchos incurrieron, tampoco habia verdadera libertad religiosa si el Estado se inhibe. No proteger a una en particular no significa que no deba hacerlo con ninguna, sino que debe proteger a todas las religiones que profesen sus súbditos; a pacto, empero, de revisar profundamente el concepto mismo de proteger. Ya no cabe entenderlo en el sentido de convertir la religión y la fe en elemento constitutivo de la Nación, de su unidad política o aun cultural. La aseveración que en su tiempo hizo V.A. Belaúnde: "El catolicismo que es y ha sido la gran fuerza educadora, la base de nuestra cohesión nacional, la fuente de nuestra moralidad colectiva, el fundamento de nuestra vida de familia"(2), como quiera que haya sido en el

(2) BELAUNDE, Víctor Andrés: "La Realidad Nacional", Ed. Mercurio Peruano, Lima 1945 , p. 284. 
pasado, ahora nadie la subscribiría totalmente. Es incompatible tanto con la configuración política del mundo como con la purificación intema de la misma religión, el considerarla "base de nuestra cohesión nacional". Los otros elementos siguen siendo válidos, pero hay que adscribirlos no sólo al catolicismo sino a todas las religiones que profesan los peruanos. $Y$ si ahora hay peruanos que no profesan ninguna religión, también su conciencia atea merece positivo respeto.

Tiene que ser asi porque el fundamento de la libertad religiosa puesto por el Vaticano II es "La dignidad de la persona humana"(D.H.No.2), no "la verdad intrínseca de la religión". Acerca de ésta, -esto es, acerca de la verdad religiosa-, el Estado no es competente. Por consiguiente para el Estado todas las religiones deben tener igual derecho, lo mismo que łos no-religiosos o ateos. Entiéndase sin embargo claramente que no son la verdad y el error los que merecen igual derecho sino las conciencias humanas que los profesan. Lo otro sería, además de un contra-sentido filosófico, un indiferentismo destructor de toda religión y, para el creyente, un pecado de infidelidad.

De todo lo dicho se concluye, y así lo refleja la actual Constitución, que el Estado no puede ser Confesional, esto es, declarar a una Religión como "Religión del Estado". La confesionalidad fue un resabio de las teocracias dominantes en todo el mundo antiguo. Exorcizadas doctrinalmente por el cristianismo, en la práctica su desaparición demandó un proceso largo y árduo, que no ha concluído. Aún existen Estados de confesionalidad protestante, ortodoxa, musulmana, budista, la israelita y también algunos católicos. Estos van desapareciendo rápidamente (el caso más reciente es España) de acuerdo con el Vaticano II. Se espera que hagan lo propio las otras religiones y sobre todo aquellos Estados que, con expresión paradójica, hay que llamar de confesionalidad atea. Este fenómeno, inaudito en la historia, se da de manera extrema y explícita en Albania, y en mayor o menor medida, directa o indirectamente, en los otros países socialistas.

Respecto del Perú, la Constitución de 1933 todavía conservaba una confesionalidad católica moderada (Cfr. el Art. 2320) que desapareció en la nueva, como diremos en el 40. punto de nuestra exposición. Pero antes:

\section{III: A QUE DEBE RENUNCIAR (Y RENUNCIO) EL ESTADO PERUANO:}

La Constitución de 1933 le atribuía ciertas facultades sobre la iglesia -heredadas del pasado- que, como se esperaba y el Vaticano II postulaba, no figuran en la nueva Constitución. Dichas atribuciones, conocidas con el nombre de "Patronato Nacional", fue, durante la República, el sucedáneo del "Patronato Regio". Este, como se sabe, era el derecho concedido por la Santa Sede a los Reyes de España desde el inicio de la Colonia. de proponer a sujetos idóneos para los diversos cargos, dignidades y beneficios eclesiásticos, a cambio del Patronato (protección privilegiada) que ellos (los Reyes) ejercían en favor de la 
acción de la iglesia católica. Al sobrevenir la Independencia, el Estado peruano reivindicó ese mismo Patronato, llamado ahora Nacional.

El nombramiento de las dignidades eclesiásticas - sobre todo de los Obispos- es un acto esencialmente religioso (como la designación de Prefectos Departamentales es un acto político). Cualquier ingerencia del Estado, por muy reconocida que haya sido y aun en el caso de ser ejercida por reyes o gobernantes sinceramente católicos, supone tal contrasentido intrínseco que con razón V.A. Belaúnde, en el libro ya citado, ¡escrito en 1931! pudo decir: "El gran cáncer de la iglesia colonial fue su sometimiento al rey; la gran desgracia de la iglesia durante la República ha sido su dependencia del Presidente y los nombramientos episcopales por el Congreso. El resultado ha sido las infelices designaciones eclesiásticas; la unión de la política y la religión"(3).

Durante la República el daño fue más real porque el Patronato fue revestido de una ideología teológico-filosófico-política, conocida con el nombre general de Regalismo que marcó el pensamiento religioso de la Independencia. Consistía en exigir regalias (privilegios extremos) en favor de los reyes y del Estado sobre la iglesia(4). Como muestra podemos recordar, más que a ese extraño y polifacético personaje, Manuel L. Vidaurre, que en el Congreso de Panamá (1830) presentó un proyecto de Gobierno ( $y$ y dedicado nada menos que al Papa! ) en el que venía a proclamar la independencia del episcopado nacional respecto del Pontífice; pódemos recordar, decimos, a un ilustre autor de mucho más alto vuelo intelectual e influjo, como fue Francisco de Paula González Vigil. Su obra "Defensa de la autoridad de los Gobiernos y de los Obispos contra las pretensiones de la Curia Romana"(5) tuvo tan amplia repercusión, incluso fuera del Perú, que - junto con otras europeas- fue el fondo de doctrinas más o menos heterodoxas contra las que el Papa Pío IX alertó en la epístola "Multiplices inter" (10 de junio, 1851) y luego se recogieron en esa colección de "Errores" que se llamó "Sílabo", varios de los cuales están sacados del libro de González Vigil(6). El No. 51 dice textualmente: "El gobiemo laico tiene el derecho de destituir a los obispos del ejercicio del Ministerio pastoral y no está obligado a obedecer al Romano Pontífice en lo que se refiere a la institución de obispados y obispos"'(7).

(3) O.c. p. 128

(4) El Regalismo revistió diferentes modalidades: El Galicanismo desde el s. XVII, en Francia, atribuía al Poder Civil el "placitum regium", es decir, el derecho de vigilar e influir en las ordenaciones eclesiásticas. El Febronianismo, s. XVIII en varios Estados alemanes, hacía del Estado una especie de tutor de la iglesia. El Josefinismo, fue la versión austriaca del Febronianismo.

(5) Lima, 1848 (Imprenta Huidobro), en 6 tomos de 300 apretadas páginas cada uno.

(6) Son los Nos 15;21;23;30:51;54 y 68. Cfr. las "fuentes" del "Enchiridion Symbolorum" Dz. - Sch. 2901 ss.

(7) Dz - Sch. No. 2951 
Esta doctrina - desde luego mitigada- resonó en el "Patronato Nacional" que oficialmente fue reinstaurado en el Perú por Nicolás de Piérola (por supuesto con el consentimiento del Papa) con el decreto del 27 de enero de 1880 , que luego pasó al derecho constitucional y la Constitución de 1933 recogió en estos artículos principales:

Art. 233o.: "El Estado ejerce el Patronato Nacional conforme a las leyes y a las prácticas vigentes";

Art. 1230.: "Son atribuciones del Congreso... Crear nuevos Arzobispados y Obispados, o suprimir los ya existentes, a solicitud del Poder Ejecutivo"( 8 )

Art. 1540., 23-24: "Los eclesiásticos peruanos que deban ocupar las vacantes de los Arzobispados y Obispados, serán designados por el Presidente de la República, en Consejo de Ministros. El Jefe del Estado hará la presentación ante la Santa Sede y dará el pase a las bulas respectivas"( $(9)$.

Art 1540. 25: "Son atribuciones del Presidente de la República... Hacer presentaciones para las dignidades y canongias de las catedrales y para los curatos y demás beneficios eclesiásticos" Inc. 26: “... Conceder o negar el pase.. a los Decretos conciliarios, Breves y Rescriptos Pontificios; y a las demás Bulas...".

Es de notar que los textos de la Constitución del 1933 citados, no obstante las enmiendas que mitigaron el texto primitivo, conservaban todavía un Regalismo mayor que en Europa, donde el Papa designaba a los Obispos y algunos gobiemos tenían el derecho de veto. Aquí, en cambio, prácticamente venía a ser lo contrario. Esto estaba, evidentemente, en pugna con la libertad religiosa y con el espíritu y la letra del Vaticano II. Con muy buen acuerdo, pues, fue abolido o ignorado por la nueva Constitución.

IV: LAS RELACIONES DE LA IGLESIA Y EL ESTADO EN LA NUEVA CONSTITUCION POLITICA DEL PERU (Promulgada el 12 de julio de 1979; y en vigencia desde el 28 de julio de 1980).

Lo dicho hasta aquí, aunque en extensión se lleva la parte del león, es sin embargo preparatorio. Constituyen los antecedentes para entender y valorar lo que la nueva Constitución consigna acerca del asunto de que estamos tratando. Vamos a exponerlo agrupáidolo en subcapítulos, quizá no tan netamente separados, pero que ayudan para la claridad.

A) TEISMO EN LA NUEVA CONSTITUCION: Desde la primera frase del Preámbulo la Asamblea Constituyente, sobre las huellas de todas las Asambleas Legislativas que aprobaron las diversas Cartas Magnas a partir del Congreso

(8) Conforme a la enmienda constitucional de la Ley 9166.5 set. 1940.

(9) Conforme al Art 30. de la Ley 13?39. 20 Nov. 1961, que enmendó a la Cisisticución. 
Constituyente de 1822, comienza: "invocando la protección de Dios". Esta profesión teista, expresión del sentir real de la inmensa mayoría de la Nación, está en perfecta consonancia con el nuevo ordenamiento propiciado por el Vaticano II que, si bien propugna la separación de la Iglesia y el Estado, de ninguna manera entiende separación como indiferencia y mucho menos como nuptura. Por lo demás, los derechos de la conciencia sinceramente atea la Constitución los reconoce en el art. 63o.: "El ciudadano que no profesa creencia religiosa puede prescindir de la invocación de Dios en su juramento". Es evidente que si la mayoría no puede imponer el ejercicio de la Religión a la minoría; tampoco ésta puede imponer la no-religión a aquélla.

B) LIBERTAD E IGUALDAD RELIGIOSA EN LA NUEVA: CONSTITUCION: Puede exponerse negativa y positivamente: Negativamente: La Constitución rechaza "toda discriminación por razones de sexo, raza, credo o condición social ("Preámbulo). Repite aproximadamente lo mismo en el art. 20.: “... sin discriminación alguna por razón de sexo, raza, religión..." (Art. 2o. 2); y lo cautela otorgando a todos el derecho "a guardar reserva sobre sus convicciones políticas, filosóficas y religiosas..." (Art. 2o., 17). Por último, con gran delicadeza y perspicacia establece: "La extradicción es rechazada si es,, por motivos de raza, religión..." (Art. 109o.). (El subrayado en los cuatro textos citados es nuestro).

Positivamente: La nueva Constitución proclama la libertad e igualdad religiosa: "Toda persona tiene derecho: A la libertad de conciencia y de religión, en forma individual o asociada... El ejercicio público de todas las confesiones es libre, siempre que no ofenda a la moral o altere el orden público" (Art. 2o. 3). Está claro, por lo que hemos visto en su respectivo lugar, que la libertad e igualdad religiosa está de acuerdo con lo enseñado por el Vaticano II (D.H. nn. 4 y 6). El texto constitucional (Art. 2o. 3) comentario-interpretación de las siguientes interpretaciones:

"El ejercicio público...": Debe entenderse en sentido pleno, es decir, que incluye el anuncio y difusión, cosa de todo punto necesaria para una religión esencialmente doctrinal, como es el cristianismo. Que esta interpretación sea conforme a la mente del legislador, lo prueba lo dicho respecto de la enseñanza de la religión en el Art. 230.

"Siempre que no altere el orden público" es una restricción a la libertad religiosa, perfectamente válida, susceptible de ser individuada, y literalmente conforme con la enseñanza del Concilio (D.H. nn. 2; 3;4). En efecto, velar por el orden público es una atribución precisa y primaria del Estado.

"Sienpre que... no ofenda a la moral", en cambio, es una restricción a la libertad religiosa textualmente ambigua. Podría poner en manos exclusivamente del Estado algo que lo desborda y a lo cual está sometido el mismo Estado, como es el determinar qué es la moral y hasta dónde se extiende. Creemos que la Constitución debió haber usado el texto del Vaticano II: "Siempre que no altere el orden moral objetivo "(D.H. n.7). El Estado tiene indiscutiblemente el derecho y deber, asimismo primario, de tutelar la moral pública incluso contra una confesión religiosa (por ej ., ¡son ejemplos históricos! , si ésta predica la 
poligamia; prohibe las transfusiones de sangre, el saludar a la bandera, etc.). Estos casos son claros; pero otros no lo son tanto. ¿cuál será el criterio de si son morales o no? Tiene que buscarse un criterio objetivo, que no lo será necesariamente el del Estado, sino el fundado en la ley y derecho natural y en la metafísica y analítica del hombre. Esto debia expresarse en el texto constitucional añadiendo la palabra "...no ofenda a la moral objetiva"; o en todo caso debe interpretarse en este sentido.

\section{C) RELACIONES IGLESIA-ESTADO EN LA NUEVA CONSTITUCION:}

Están expresadas, creemos que de manera magistral, en un breve artículo: "Dentro de un régimen de independencia y autonomía, el Estado redonoce a la Iglesia Católica como elemento importante en la formación histórica, cultural y moral del Perú. Le presta su colaboración. El Estado puede también establecer formas de colaboración con otras Confesiones" (Art. 860.).

Nos parece un gran acierto esta formulación porque da en el verdadero espíritu de la doctrina del Vaticano II, el cual, ciertamente, no quiere la confesionalidad (G.S.76; D.H.3), pero tampoco la pura y simple separación. Algunos teólogos y canonistas expresan esta nueva modalidad propiciada por el Concilio que el Estado debe ser Laico, pero no Laicista. Ello signifca que entre el Estado Confesional (que proclama a una religión determinada, "Religión del Estado"), y el Estado Laicista (que se proclama no-religión, libre de toda referencia a Dios) se da el Estado que podría llamarse Religioso (en oposición al ateo o indiferente); Sacral (en oposición a secularizado); pero que consideramos preferible llamar LAICO (en oposición a Laicista).

El Laicismo históricamente data de la época del Iluminismo (o "Ilustración", "Siglo de las Luces", el XVIII), es decir, de esa concepción filosófica inmanentista que, más que negar explícitamente, relegó a Dios y los valores trascendentales al dominio exclusivo de lo privado y de la conciencia individual. Pero Laicismo no se identifica con Laico. Este término es canónico y bíblico. En la Sagrada Escritura designa al Santo Pueblo (laos) de Dios. Entendería muy mal la separación del Estado y la Iglesia preconizada por el Concilio, el que considerara que el Estado deba o pueda ser indiferente en materia religiosa. Esto queda terminantemente excluído de la intención del Vaticano II, como lo afirmó el principal autor del esquema de la Declaración "Dignitatis Rumanae", el P. Murray, pocos días después de promulgada(10).

La laicidad del Estado significa que tiene un fin propio (G.S. 36) válido por si mismo y que debe alcanzar por sus propios medios naturales. Pero ese fin no es absolutamente último (eterno, escatológico), sino penúltimo (temporal, terreno). El Estado sólo tiene un fin penúltimo; los súbditos lo tienen también

(10) Cfr. MURRAY, J. Countriney, S.J.: Osservazioni sulla Dichiarazione Conciliare Dignitatis Humanae": Civ. C $1965-\mathrm{IV}-536 \mathrm{ss}$. 
último, como admirablemente lo reconoce, si bien con otros términos, el Preambulo de la Nueva Constitución al decir':"Los hombres, iguales en dignidad, tienen derechos de validez universal, anteriores y superiores al Estado". Es claro que el Estado no es competente respecto del fin último, y no es su misión, sino de la Iglesia, el procurarlo directamente. Sin embargo el Estado, no sólo no debe obstaculizarlo, pero ni siquiera ser indiferente: debe contribuir indirectamente, ayudando a sus súbditos para que dispongan de los meàios para alcanzarlo. Esto. lo cumple la nueva Constitución por lo menos lo suficiente como para que el católico de un país como el Perú, que fue moderadamente confesional hasta ayer, no tenga por qué considerar un retraso el Estado Laico que refleja la presente Constitución. Debe más bien considerarla como la traducción jurídica actual de la permanente libertad del acto de fe.

Otro gran acierto de la nueva formulación es haber puesto: "Dentro de un régimen de independencia y autonomia", y no "de separación" del Estado y la iglesia. La palabra separación, además de caber en todas las constituciones (incluída la de Rusia), en los paises latinos tiene pésimo abolengo. Nació bajo el signo de la ruptura de relaciones entre la Iglesia y el Estado (Francia, Méjico, Ecuador...) y conserva su marca. En cambio la fórmula adoptada, lejos de implicar ruptura se armoniza perfectamente con lo que a continuación añade el texto, esto es, reconocer a la "Iglesia Católica como elemento importante en la formación histórica, cultural y moral del Perú". Reconocimiento del todo compatible con el presente pluralismo religioso, la plena libertad religiosa y la igualdad $j u$ rídica de todas las religiones; pues es un hecho objetivo que la Iglesia Católica no es una religión de ayer. Está profundamente vinculada al inicio histórico del Perú y desde entonces insertada en su moral, forma de vida, escala de valores, tradiciones, costumbres, artes, lenguaje, etc. Asi como decía un autor al inicio. de los debates sobre esta materia, "sin pugnar con lo esencial, se mantiene un equilibrio entre lo que se legisla y lo que se vive en cada sociedad. Las leyes tienen - deben tener-padre y madre: legislador y vivencias sociales“( $(11)$.

El último elemento que merece destacarse en este Art. 860. es: "Le presta su colaboración. El Estado puede también establecer formas de colaboración. con otras confesiones". Otras confesiones aqui está por "otros credos religiosos"o simplemente "Otras religiones", no sólo "otras confesiones cristianas" a las que por el condicionamiento cultural solemos referimos con frecuencia con ese término. Esta restricción sería totalmente extraña a la doctrina del Vaticano II y a los textos de la misma Constitución sobre la libertad religiosa que vimos antes.

Alguna de esas "formas de colaboración" con la iglesia católica han quedado plasmadas ya en un "Acuerdo entre la Santa Sede y la República del Perú" (19 de julio, 1980), suficientemente detallado y claro, al cual remitimos a las personas interesadas; pero no es tema del presente estudio.

(11) CALVO OTERO, J.: "Relaciones Modemas entre la Iglesia y el Estado": "Concilium", 58 (1970) p. 257. 